\title{
Long-Term Load Forecasting of Southern Governorates of Jordan Distribution Electric System
}

\author{
Aouda A. Arfoa \\ Electrical Engineering Department, Tafila Technical University, Tafila, Jordan \\ Email: oda@ttu.edu.jo \\ Received 24 December 2014; accepted 23 May 2015; published 28 May 2015 \\ Copyright (c) 2015 by author and Scientific Research Publishing Inc. \\ This work is licensed under the Creative Commons Attribution International License (CC BY). \\ http://creativecommons.org/licenses/by/4.0/ \\ c) (i) Open Access
}

\begin{abstract}
Load forecasting is vitally important for electric industry in the deregulated economy. This paper aims to face the power crisis and to achieve energy security in Jordan. Our participation is localized in the southern parts of Jordan including, Ma'an, Karak and Aqaba. The available statistical data about the load of southern part of Jordan are supplied by electricity Distribution Company. Mathematical and statistical methods attempted to forecast future demand by determining trends of past results and use the trends to extrapolate the curve demand in the future.
\end{abstract}

\section{Keywords}

Long-Term Load Forecasting, Peak Load, Max Demand and Least Squares

\section{Introduction}

In the absence of perspective planning, the state faces power crisis. The important factors which lead to power crisis are: 1) low utilization of existing energy sources; 2) low utilization of existing generating capacity; 3) faculty planning and defective execution of projects; 4) inadequate linking of transmission network; 5) absence of efficient and integrated operations of different power stations in a system; 6) political influences in decisions on locations of power stations due to lack of studies and researches.

Jordan suffers from the lack of the electrical energy due to the above mentioned factors especially the low utilization of existing energy sources, absence of long term planning of energy and no attentions or supports are given to the researchers and personnel of power stations.

Perspective planning of the system should be based on proper forecasting of the load of the system, availability of generating stations and their improvements, combination of resources, economic considerations, streng- 
thening and coordinating various existing systems and above all the availability of the adequate finance and management skill for realizing the benefits of the perspective planning.

It is first necessary to find out the load requirements of the area where electricity is to be supplied. This depends on the population of area, density of population, standards of living, industrial development and the cost of energy; when we talk about these factors we talk about people's energy security and country security which must be achieved. In the southern part of Jordan, the load consists mainly of domestic load like, lights, fan heaters, refrigerators, air conditioners, radio, television, electric cookers, electric water heaters and low power motors. Commercial load like lighting for big supermarket and street lighting. Industry load is excluded from this study because the maximum demand of industries in southern part of Jordan was taking into account the period of establishing these factories (and they have own substations and own tariff).

Load forecasting can be broadly divided into three categories: short-term forecasts which are usually from one hour to one week, medium forecasts which are usually from a week to a year, and long-term forecasts which are longer than a year [1]. Traditional studies for long-term load forecasting were based on regression method, which could not provide a true representation of power system behavior in a volatile electricity market. Many studies present traditional methods like neural networks, genetic algorithms, fuzzy rules, which support vector machines, wavelet networks and expert systems [2] [3], while [4]-[6] introduce two approaches based on regression method and artificial neural network (ANN) for long-term load forecast by applying fuzzy sets to ANN for modeling long-term uncertainties and compare the enhanced forecasting results with those of traditional methods. There are also some researchers present artificial neural network (ANN) combined with linear regression [7]. In [8], energy data of several past years were used to train an adaptive network based on fuzzy inference system (ANFIS). Also in [9], a new hybrid forecast engine is proposed; the proposed engine has an iterative training mechanism composed of a novel stochastic search technique and Levenberg-Marquardt (LM) learning algorithm. Another method combined with artificial neural network supports vector machine (SVM). A novel dynamic architecture for artificial neural network (DAN2) method was used in load forecasting; the structure of DAN2 was automatic formed by training [10].

In this paper, by using the max demand data which is recorded from 2005 to 2013 and employing the least squares regression, peak load demand for 2014-2023 is forecasted. The results are validated by using the real data of 2014.

\section{Least Squares Method}

Generally, load forecasting methods are mainly classified into two categories: classical approaches and nonclassical techniques. Classical approaches are based on statistical methods and forecast future value of a variable by using a mathematical combination of the historic information but this way have week prediction result, least squares method is most power full techniques will be used in forecasting, load forecasting is of the most difficult problems in distribution system planning and analysis. However, not only historical load data of a distribution system play a very important role on peak load forecasting, but also the impacts of meteorological and demographic factors must be taken into consideration so least squares method is the best method to solve this kind of problem [11].

Let $D=$ demand of electrical power ( $\mathrm{kW}$ or MW).

$y=$ the year in which the demand is considered.

$y^{o}=$ base year.

Then the exponential growth of demand with time would be expressed as: $D=\mathrm{e}^{a+b\left(y-y^{o}\right)}$

Where: $a, b=$ constants.

In order to evaluate the constants a and $b$, based on actual demand data over a number of year, put $y-y^{0}=Y$.

$$
\begin{aligned}
& \text { then: } D=\mathrm{e}^{a+b Y} \\
& \text { then: } \ln D=a+b Y \text {. } \\
& \text { Let } V=\ln D \\
& \text { then } V=a+b Y
\end{aligned}
$$

Equation (1) is an equation relating $V$ and $Y$ in a linear fashion.

Suppose that the demand for consecutive years are given as: $D_{1}, D_{2}, D_{3}, \cdots, D_{n}$. The plot of $V=f(Y)$ is shown in Figure 1. 


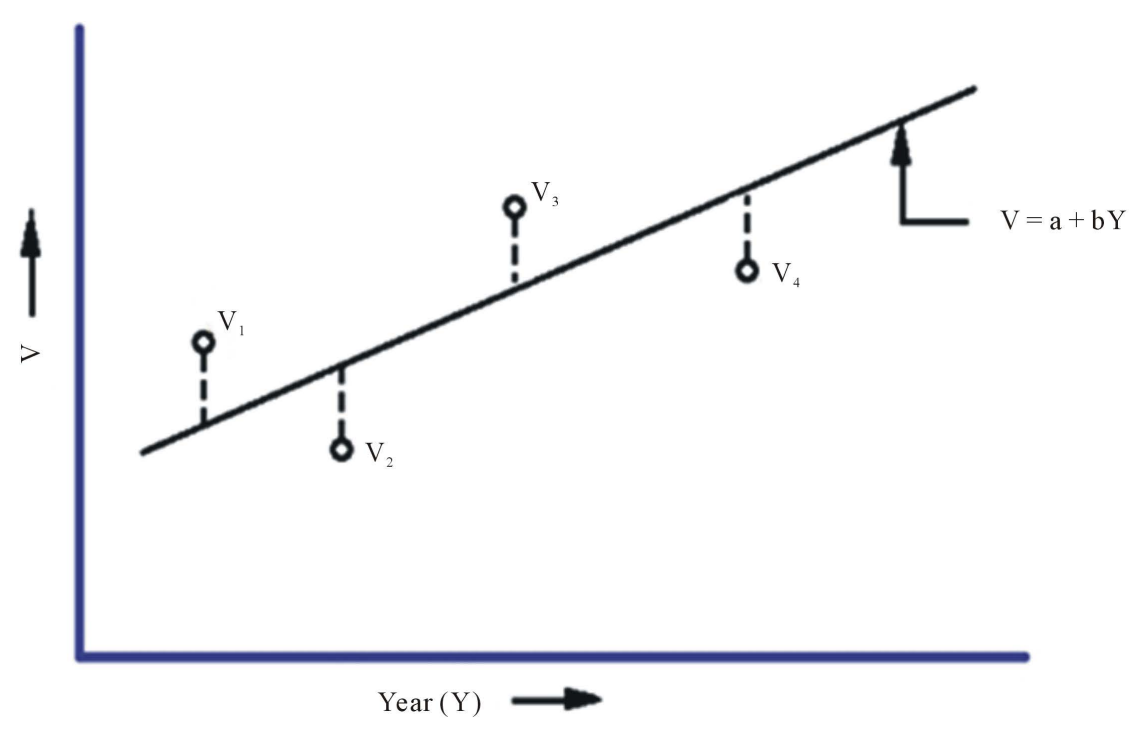

Figure 1. Least squaresthe demand for consecutive years.

Corresponding to various values of $Y_{i}$ 's there are $V_{i}$ 's. All the $V_{i}$ 's are randomly distributed as shown in the last figure. For an exponential growth, $V=a+b Y$. In order to correctly assess the demand, the sum of the squares of the errors committed by such approximation should be minimzed [12], i.e.

$s=\sum_{i=1}^{n}\left[V_{i}-\left(a+b Y_{i}\right)\right]^{2}$ should be minimum. Conditions for $s$ to be minimum are:

$$
\frac{\partial s}{\partial a}=0 \text { and } \frac{\partial s}{\partial b}=0
$$

Then: $\frac{\partial s}{\partial a}=\sum_{i=1}^{n} 2\left[V_{i}-\left(a+b Y_{i}\right)\right](-1)=0$

$$
\sum_{i=1}^{n} V_{i}=n a+b \sum_{i=1}^{n} Y_{i}
$$

Also: $\frac{\partial s}{\partial b}=\sum_{i=1}^{n} 2\left[V_{i}-\left(a+b Y_{i}\right)\right](-1) Y_{i}=0$

$$
\sum_{i=1}^{n} V_{i} Y_{i}=a \sum_{i=1}^{n} Y_{i}+b \sum_{i=1}^{n} Y_{i}^{2}
$$

Thus, Equations (2) and (3) provide the conditions for the sum of the least squares of the deviation to be minimum.

For simplifying further, let $\sum_{i=1}^{n} Y_{i}=0$

From Equation (1), we have:

$$
\begin{array}{r}
a=\frac{1}{n} \sum_{i=1}^{n} V_{i} \\
\text { And } b=\frac{\sum_{i=1}^{n} Y_{i} V_{i}}{\sum_{I=1}^{n} Y_{i}^{2}}
\end{array}
$$

Thus Equations (4) and (5) would enable us to evaluate the constants $a$ and $b$ so as to minimize the error in load forecasting. 


\section{Distribution Electric System of Southern Governorates in Jordan}

The distribution of electric system of southern governorates in Jordan cover four governorates Ma'an, Aqaba, Tafila and Karak. The total number of constructed substations and their accumulative capacity in the distribution areas lha1 belong to the company until the end of 2013 was (4531) with a capacity of 2542 MVA, at the end of 2013, the total length of medium and low voltage for both overhead and underground networks have been reached $(11,650) \mathrm{km}[13]$, Figure 2 and Figure 3 represent the main substation in each governorate Karak, Ma'an, Tafila and Aqaba

\section{i. Karak Forecasting}

Referring to nine years load data, we found the Max demand of each years as shown in Table 1 by using this data in Figure 2, and applying the least squares to find the Max Demand for next ten years Table 2 and Table 3 shown the Max Demand for next ten years.

In the last column of Table 3, we found the value of forecasting for next ten years; then we put these values on the axis, then we have to generate the curve in Figure 4.

After we found the values of Max demand of next years, we will be able to predict the year for which you want the new plant, in next page Table 4 show this. Note here is that the pregnancy has exceeded the maximum allowable load before it is predictable.

\section{ii. Tafila Forecasting}

In appendix A found the table of last nine years, then we found the max demand of each years and plot in this Table 5. Then like us these values in the form of the curve in Figure 5 and Figure 6.

Then we use the least squares to find the Max Demand for next ten years. When use the least squares generate Table 6 and Table 7.
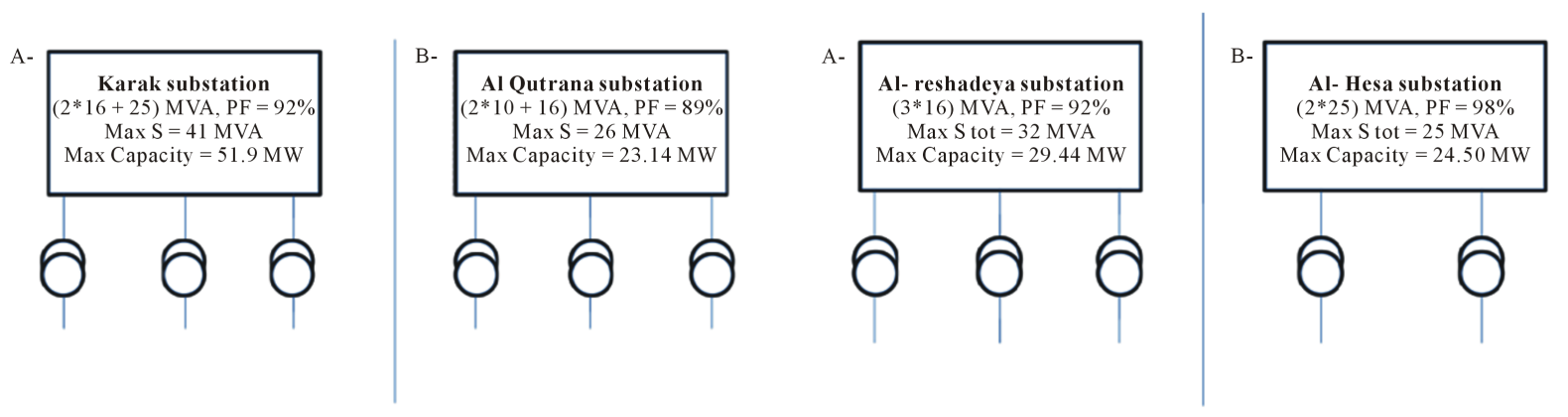

Figure 2. The main substation at Karak and Tafila governorate.
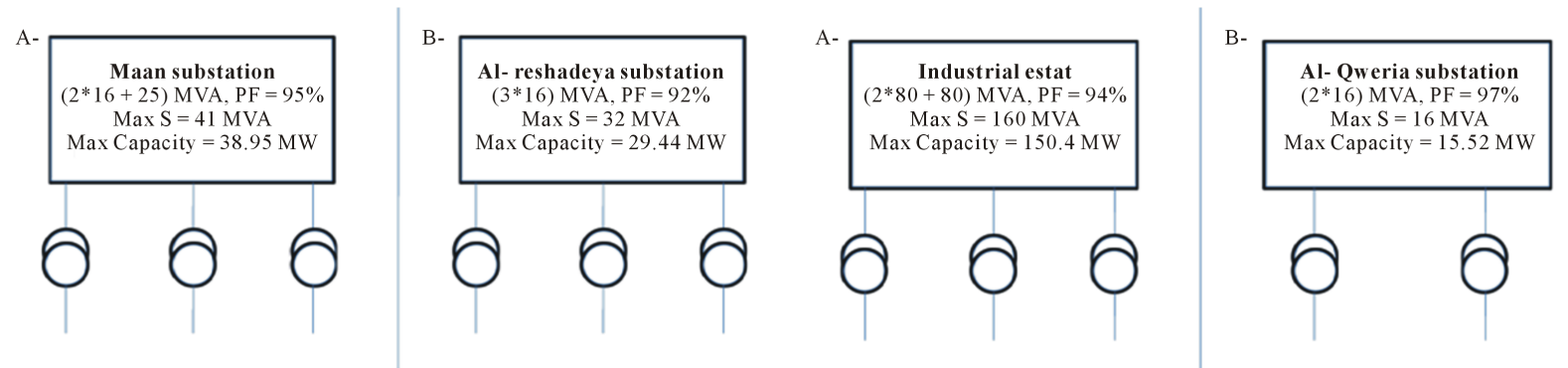

Figure 3. The main substation at Ma'an and Aqaba governorate.

Table 1. Max demand of Karak governorate for nine years.

\begin{tabular}{cccccccccccc}
\hline City & & $\mathbf{2 0 0 5}$ & $\mathbf{2 0 0 6}$ & $\mathbf{2 0 0 7}$ & $\mathbf{2 0 0 8}$ & $\mathbf{2 0 0 9}$ & $\mathbf{2 0 1 0}$ & $\mathbf{2 0 1 1}$ & $\mathbf{2 0 1 2}$ & $\mathbf{2 0 1 3}$ \\
\hline \multirow{2}{*}{ Karak } & Karak & 25.65 & 41.38 & 39.66 & 43.07 & 36.20 & 36.20 & 45.24 & 51.88 & 50.93 \\
& Qutraneh & 16.86 & 17.15 & 18.34 & 19.31 & 22.19 & 22.19 & 18.70 & 19.96 & 20.18 \\
& karak total & 48.32 & 58.53 & 58 & 59.3 & 71.02 & 71.02 & 76.66 & 84.04 & 84.38 \\
\hline
\end{tabular}


Table 2. Least squares co-officiant.

\begin{tabular}{ccccccc}
\hline Last Years & Max $\boldsymbol{D}$ & $\boldsymbol{D}_{\boldsymbol{i}}^{\prime}=\mathbf{D} / \mathbf{1 0}$ & $\boldsymbol{V i}=\mathbf{l n} \boldsymbol{D}_{\boldsymbol{i}}^{\prime}$ & $\boldsymbol{Y}_{\boldsymbol{i}}$ & $\boldsymbol{V}_{\boldsymbol{i}} \boldsymbol{Y}_{\boldsymbol{i}}^{\prime}$ & $\boldsymbol{Y}_{\boldsymbol{i}}^{\wedge} \mathbf{2}$ \\
\hline $\mathbf{2 0 0 5}$ & 48.32 & 4.832 & 1.57526 & -4 & -6.30104 & 16 \\
$\mathbf{2 0 0 6}$ & 58.53 & 5.853 & 1.766954 & -3 & -5.30086 & 9 \\
$\mathbf{2 0 0 7}$ & 58 & 5.8 & 1.757858 & -2 & -3.51572 & 4 \\
$\mathbf{2 0 0 8}$ & 59.3 & 5.93 & 1.780024 & -1 & -1.78002 & 1 \\
$\mathbf{2 0 0 9}$ & 71.02 & 7.102 & 1.960376 & 0 & 0 & 0 \\
$\mathbf{2 0 1 0}$ & 71.02 & 7.102 & 1.960376 & 1 & 1.960376 & 1 \\
$\mathbf{2 0 1 1}$ & 76.66 & 7.666 & 2.036795 & 2 & 4.07359 & 4 \\
$\mathbf{2 0 1 2}$ & 84.04 & 8.404 & 2.128708 & 3 & 6.386123 & 9 \\
$\mathbf{2 0 1 3}$ & 84.38 & 8.438 & 2.132745 & 4 & 8.530981 & 16 \\
\hline
\end{tabular}

Table 3. Max Demand for next ten years.

\begin{tabular}{|c|c|c|c|c|c|c|}
\hline Next Years & Sum of $V_{i}$ & Sum of $Y_{i}$ & Sum of $V_{i} Y_{i}$ & $a$ & $\boldsymbol{b}$ & Max D \\
\hline 2014 & & & & & & 93.716134 \\
\hline 2015 & & & & & & 100.26608 \\
\hline 2016 & & & & & & 107.27381 \\
\hline 2017 & & & & & & 114.77132 \\
\hline 2018 & 17.0990979 & 0 & 4.05342603 & 1.8999 & 0.067557 & 122.79285 \\
\hline 2019 & & & & & & 131.375 \\
\hline 2020 & & & & & & 140.55698 \\
\hline 2021 & & & & & & 150.3807 \\
\hline 2022 & & & & & & 160.89101 \\
\hline 2023 & & & & & & 172.1359 \\
\hline
\end{tabular}

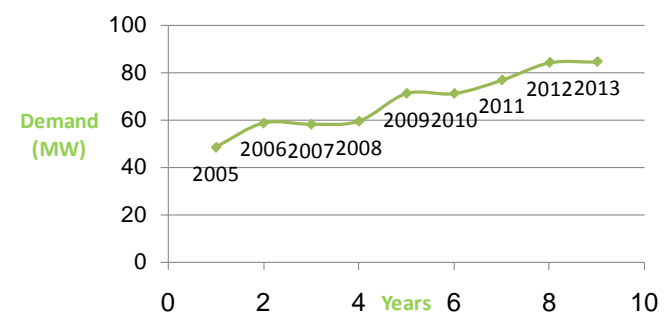

Figure 4. Total max demand for Karak governorate.

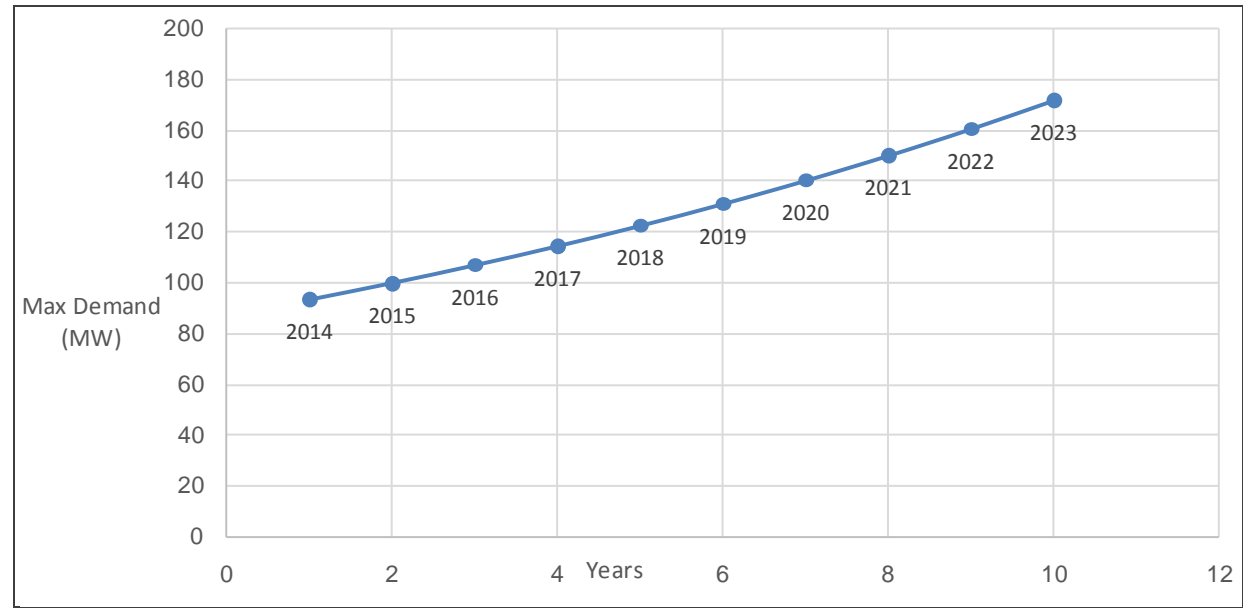

Figure 5. Max demand of next years. 


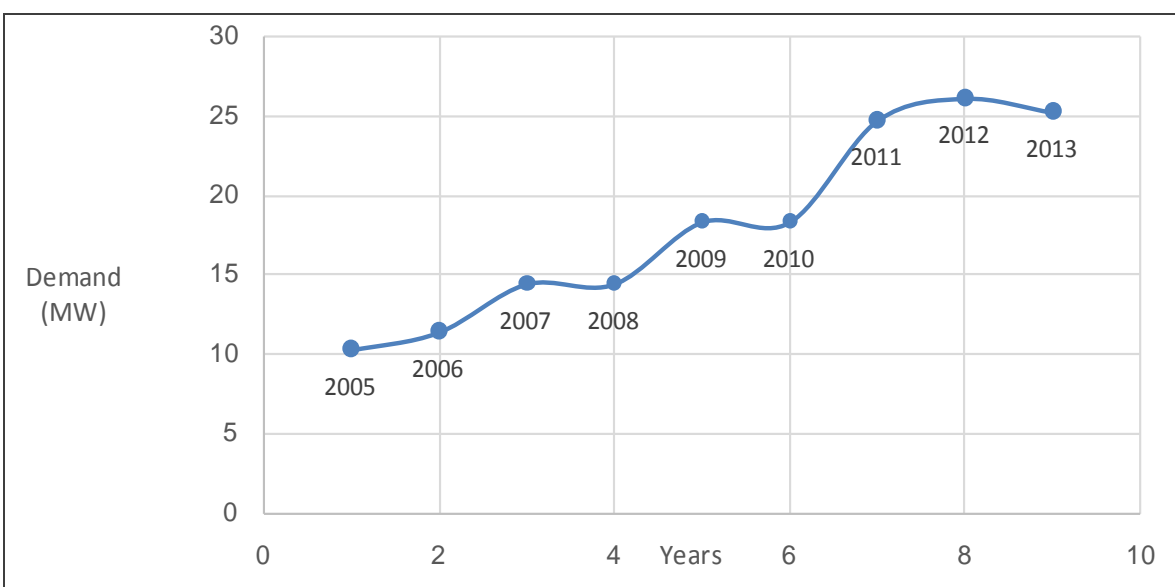

Figure 6. Tafila total max demand.

Table 4. Karak forecasting for 10 years.

\begin{tabular}{ccccccccccccccc}
\hline Sub & Max $\mathbf{D}$ & $\mathbf{8 5 \% - \mathbf { 9 0 } \%}$ & $\mathbf{2 0 1 4}$ & $\mathbf{2 0 1 5}$ & $\mathbf{2 0 1 6}$ & $\mathbf{2 0 1 7}$ & $\mathbf{2 0 1 8}$ & $\mathbf{2 0 1 9}$ & $\mathbf{2 0 2 0}$ & $\mathbf{2 0 2 1}$ & $\mathbf{2 0 2 2}$ & $\mathbf{2 0 2 3}$ \\
\hline Karak & 51.9 & $44.12-46.71$ & 54.10 & 57.35 & 60.79 & 64.44 & 68.30 & 72.40 & 76.75 & 81.36 & 86.24 & 91.419 \\
Qutraneh & 23.14 & $19.67-20.83$ & 21.65 & 22.15 & 22.65 & 23.17 & 23.69 & 24.24 & 24.79 & 25.35 & 25.93 & 26.523 \\
karak total & 75.04 & $63.79-67.54$ & 93.716 & 100.27 & 107.27 & 114.77 & 122.79 & 131.38 & 140.56 & 150.38 & 160.89 & 172.14 \\
\hline
\end{tabular}

Table 5. Max demand of Tafila governorate for nine years.

\begin{tabular}{|c|c|c|c|c|c|c|c|c|c|c|}
\hline City & & 2005 & 2006 & 2007 & 2008 & 2009 & 2010 & 2011 & 2012 & 2013 \\
\hline \multirow{3}{*}{ Tafileh } & Hasa & 4.80 & 3.76 & 6.60 & 5.90 & 8.56 & 8.56 & 11.57 & 12.98 & 12.72 \\
\hline & Rashedieh Tafileh & 6.08 & 7.65 & 7.84 & 8.81 & 9.78 & 9.78 & 13.16 & 13.13 & 12.53 \\
\hline & Tafileh Total & 10.28 & 11.4 & 14.44 & 14.44 & 18.34 & 18.34 & 24.73 & 26.12 & 25.24 \\
\hline
\end{tabular}

Table 6. Least squares co-officiant.

\begin{tabular}{|c|c|c|c|c|c|c|}
\hline Last Years & $\operatorname{Max} D$ & $D_{i}^{\prime}=D / 10$ & $V_{i}=\ln D_{i}^{\prime}$ & $Y_{i}$ & $\boldsymbol{V}_{i} \boldsymbol{Y}_{i}^{\prime}$ & $Y_{i} \wedge 2$ \\
\hline 2005 & 10.28 & 1.028 & 0.027615 & -4 & -0.11046 & 16 \\
\hline 2006 & 11.4 & 1.14 & 0.131028 & -3 & -0.39308 & 9 \\
\hline 2007 & 14.44 & 1.444 & 0.367417 & -2 & -0.73483 & 4 \\
\hline 2008 & 14.44 & 1.444 & 0.367417 & -1 & -0.36742 & 1 \\
\hline 2009 & 18.34 & 1.834 & 0.606499 & 0 & 0 & 0 \\
\hline 2010 & 18.34 & 1.834 & 0.606499 & 1 & 0.606499 & 1 \\
\hline 2011 & 24.73 & 2.473 & 0.905432 & 2 & 1.810864 & 4 \\
\hline 2012 & 26.12 & 2.612 & 0.960116 & 3 & 2.880349 & 9 \\
\hline 2013 & 25.24 & 2.524 & 0.925845 & 4 & 3.70338 & 16 \\
\hline
\end{tabular}


In the last column of Table 7, we found the value of forecasting for next ten years, then we put these values on the axis, then we have to generate the curve in Figure 7.

After we found the values of Max demand of next years, we will be able to predict the year for which you want the new plant, in next page Table 8 show this.

When we see to the Table 8, in 2017 the value of Demand is between $85 \%$ - 90\%, in this range we must send to the authority concerned power plants that we want during the next 3 years we want a new Plant.

iii. Ma'an Forecasting.

In appendix A found the table of last nine years, then we found the max demand of each years and plot in this Table 9.

Then like us these values in the form of the curve in Figure 8.

Then we use the least squares to find the Max Demand for next ten years. When use the least squares generate Table 10 and Table 11.

In the last column of Table 11, found the value of forecasting for next ten years, then we put these values on the axis, then we have to generate the curve in Figure 7.

After we found the values of Max demand of next years, we predicted the year for which you want the new plant, in next page Table 12 show this.

When we see to Table 12, in 2017 the value of Demand is between $85 \%$ - 90\%, in this range we must send to the authority concerned power plants that we want during the next 3 years we want a new Plant, then in end of 2019 the plant is Ready for operate and cover any increase above 100\% in that year.

Table 7. Max demand for next ten years.

\begin{tabular}{|c|c|c|c|c|c|c|}
\hline Next Years & Sum of $V_{i}$ & Sum of $\boldsymbol{Y}_{\boldsymbol{i}}$ & Sum of $V_{i} Y_{i}$ & $a$ & $b$ & $\operatorname{Max} D$ \\
\hline 2014 & & & & & & 31.914722 \\
\hline 2015 & & & & & & 36.101063 \\
\hline 2016 & & & & & & 40.836539 \\
\hline 2017 & & & & & & 46.19318 \\
\hline 2018 & 4.8978694 & 0 & 7.39529519 & 0.544208 & 0.123255 & 52.252466 \\
\hline 2019 & & & & & & 59.106565 \\
\hline 2020 & & & & & & 66.859735 \\
\hline 2021 & & & & & & 75.62991 \\
\hline 2022 & & & & & & 85.550493 \\
\hline 2023 & & & & & & 96.772386 \\
\hline
\end{tabular}

Table 8. Tafila Forecasting for 10 years.

\begin{tabular}{cccccccccccccc}
\hline Sub & Max Capacity & $\mathbf{8 5 \% - \mathbf { 9 0 } \%}$ & $\mathbf{2 0 1 4}$ & $\mathbf{2 0 1 5}$ & $\mathbf{2 0 1 6}$ & $\mathbf{2 0 1 7}$ & $\mathbf{2 0 1 8}$ & $\mathbf{2 0 1 9}$ & $\mathbf{2 0 2 0}$ & $\mathbf{2 0 2 1}$ & $\mathbf{2 0 2 2}$ & $\mathbf{2 0 2 3}$ \\
\hline Hasa & 24.5 & $20.83-22.05$ & 16.51 & 19.22 & 22.37 & 24.5 & 24.5 & 24.5 & 28.38 & 32.76 & 37.72 & 43.18 \\
Rahadieh-Tafileh & 29.44 & $25.02-26.50$ & 15.30 & 16.81 & 18.47 & 21.69 & 27.75 & 34.60 & 38.48 & 42.87 & 47.82 & 53.29 \\
Tafila total & 53.94 & $45.86-48.55$ & 31.9 & 36.09 & 40.84 & 46.19 & 52.25 & 59.10 & 66.86 & 75.63 & 85.54 & 96.47 \\
\hline
\end{tabular}

Table 9. Max demand of Ma'an governorate for nine years.

\begin{tabular}{cccccccccccccc}
\hline City & & $\mathbf{2 0 0 5}$ & $\mathbf{2 0 0 6}$ & $\mathbf{2 0 0 7}$ & $\mathbf{2 0 0 8}$ & $\mathbf{2 0 0 9}$ & $\mathbf{2 0 1 0}$ & $\mathbf{2 0 1 1}$ & $\mathbf{2 0 1 2}$ & $\mathbf{2 0 1 3}$ \\
\hline \multirow{2}{*}{ Ma’an } & Ma'an & 21.44 & 25.07 & 25.56 & 28.32 & 35.94 & 35.94 & 37.64 & 40.62 & 40.66 \\
& Rashadleh Quadiesieh & 5.01 & 7.2 & 5.42 & 5.58 & 4.1 & 4.1 & 5.42 & 3.62 & 3.65 \\
& Ma'an Total & $\mathbf{2 6 . 4 5}$ & $\mathbf{3 2 . 0 9}$ & $\mathbf{3 0 . 9 8}$ & $\mathbf{3 0 . 9 8}$ & $\mathbf{4 0 . 0 4}$ & $\mathbf{4 0 . 0 4}$ & $\mathbf{4 3 . 0 5}$ & $\mathbf{4 4 . 4 2}$ & $\mathbf{4 4 . 3 1}$ \\
\hline
\end{tabular}


Table 10. Least squares co-officiant.

\begin{tabular}{ccccccc}
\hline Last Years & Max $\boldsymbol{D}$ & $\boldsymbol{D}_{\boldsymbol{i}}^{\prime}=\boldsymbol{D} / \mathbf{1 0}$ & $\boldsymbol{V}_{\boldsymbol{i}}=\mathbf{l n} \boldsymbol{D}_{\boldsymbol{i}}^{\prime}$ & $\boldsymbol{Y}_{\boldsymbol{i}}$ & $\boldsymbol{V}_{\boldsymbol{i}} \boldsymbol{Y}_{\boldsymbol{i}}^{\prime}$ & $\boldsymbol{Y}_{\boldsymbol{i}}^{\wedge} \mathbf{2}$ \\
\hline $\mathbf{2 0 0 5}$ & 26.45 & 2.645 & 0.972671 & -4 & -3.89068 & 16 \\
$\mathbf{2 0 0 6}$ & 32.09 & 3.209 & 1.165959 & -3 & -3.49788 & 9 \\
$\mathbf{2 0 0 7}$ & 30.98 & 3.098 & 1.130757 & -2 & -2.26151 & 4 \\
$\mathbf{2 0 0 8}$ & 30.98 & 3.098 & 1.130757 & -1 & -1.13076 & 1 \\
$\mathbf{2 0 0 9}$ & 40.04 & 4.004 & 1.387294 & 0 & 0 & 0 \\
$\mathbf{2 0 1 0}$ & 40.04 & 4.004 & 1.387294 & 1 & 1.387294 & 1 \\
$\mathbf{2 0 1 1}$ & 43.05 & 4.305 & 1.459777 & 2 & 2.919554 & 4 \\
$\mathbf{2 0 1 2}$ & 44.42 & 4.442 & 1.491105 & 3 & 4.473314 & 9 \\
$\mathbf{2 0 1 3}$ & 44.31 & 4.431 & 1.488625 & 4 & 5.954501 & 16 \\
\hline
\end{tabular}

Table 11. Max Demand for next ten years.

\begin{tabular}{|c|c|c|c|c|c|c|}
\hline Next Years & Sum of $V_{i}$ & Sum of $Y_{i}$ & Sum of $V_{i} Y_{i}$ & $a$ & $b$ & $\operatorname{Max} D$ \\
\hline 2014 & & & & & & 50.492014 \\
\hline 2015 & & & & & & 53.921166 \\
\hline 2016 & & & & & & 57.583207 \\
\hline 2017 & & & & & & 61.493955 \\
\hline 2018 & 11.6162154 & 0 & 3.94247393 & 1.290691 & 0.065708 & 65.670301 \\
\hline 2019 & & & & & & 70.130282 \\
\hline 2020 & & & & & & 74.893161 \\
\hline 2021 & & & & & & 79.97951 \\
\hline 2022 & & & & & & 85.411297 \\
\hline 2023 & & & & & & 91.211982 \\
\hline
\end{tabular}

Table 12. Tafila forecasting for 10 years.

\begin{tabular}{cccccccccccccc}
\hline Substation & Max D & $85 \%-95 \%$ & 2014 & 2015 & 2016 & 2017 & 2018 & 2019 & 2020 & 2021 & 2022 & 2023 \\
\hline $\begin{array}{c}\text { Maan } \\
\begin{array}{c}\text { Rahadieh- } \\
\text { Quadiesieh }\end{array}\end{array}$ & 38.95 & $33.11-35.1$ & 38.95 & 38.95 & 38.95 & 38.95 & 38.95 & 38.95 & 41.34 & 43.9 & 46.63 & 49.55 \\
Total & 29.44 & $25.02-26.5$ & 11.58 & 15.02 & 18.7 & 22.62 & 26.82 & 31.3 & 33.96 & 36.52 & 39.25 & 42.17 \\
\hline
\end{tabular}

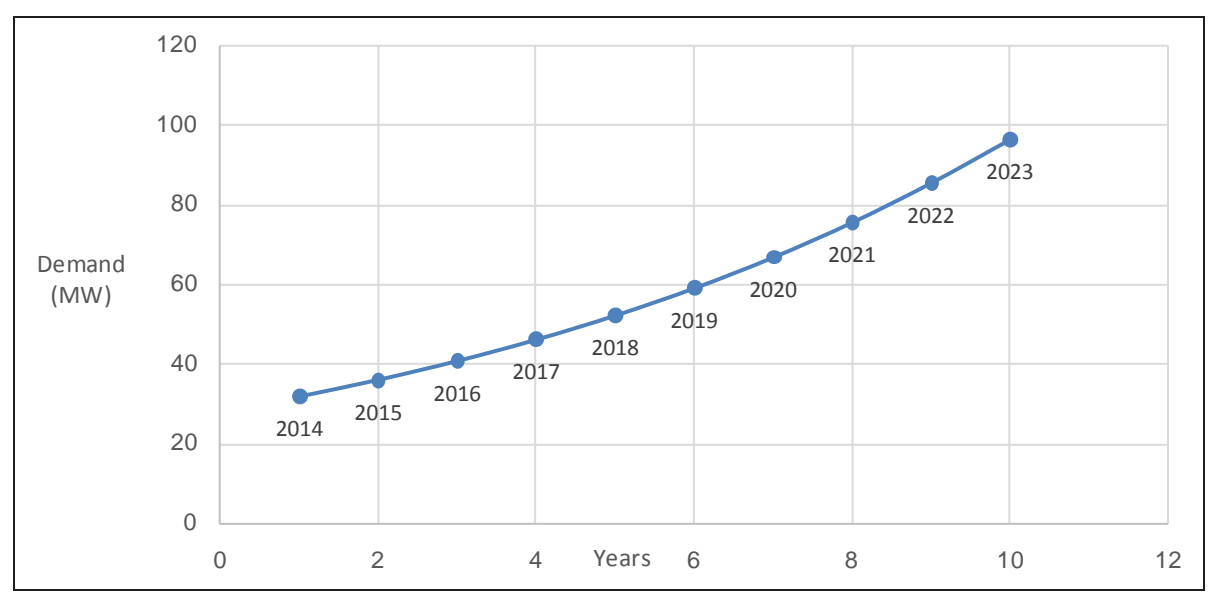

Figure 7. Tafila max demand for next 10 years. 
iv. Aqapa Forecasting.

In appendix A found the table of last nine years, then we found the max demand of each years and plot in this Table 13.

Then like us these values in the form of the curve in Figure 9 and Figure 10.

Then we use the least squares to find the Max Demand for next ten years. When use the least squares generate Table 14 and Table 15.

In the last column of Table 15, we found the value of forecasting for next ten years, then we put these values

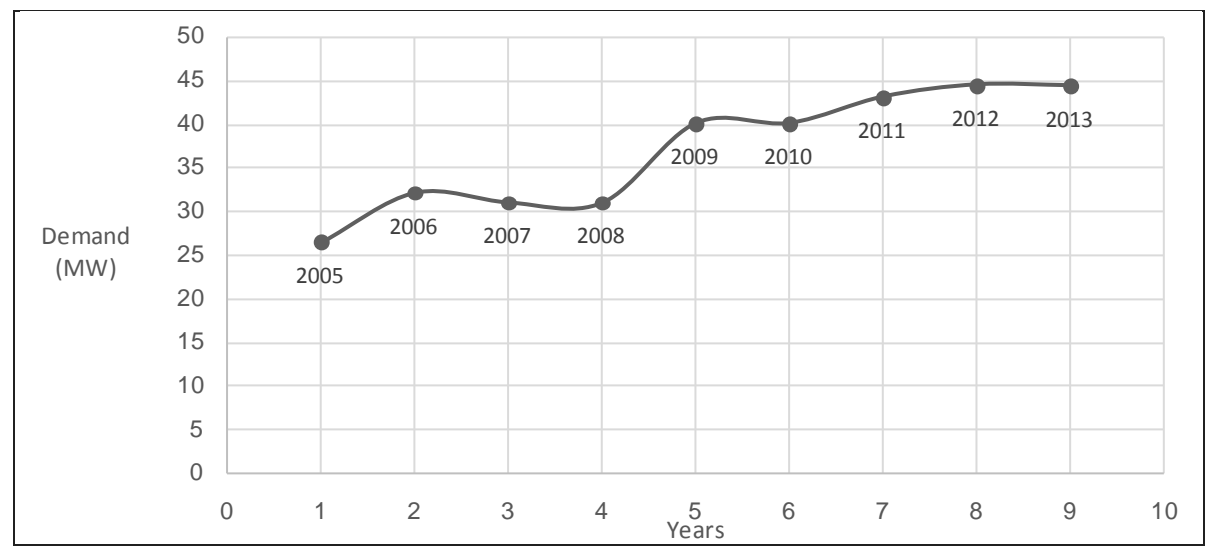

Figure 8. Ma’an total max demand.

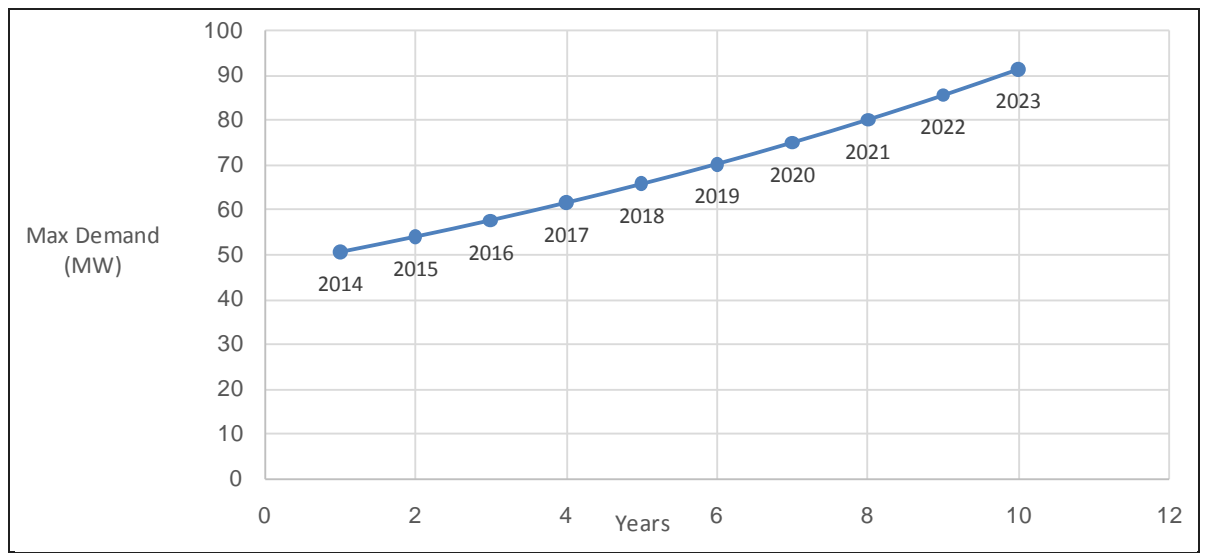

Figure 9. Next ten years forecasting of Ma’an.

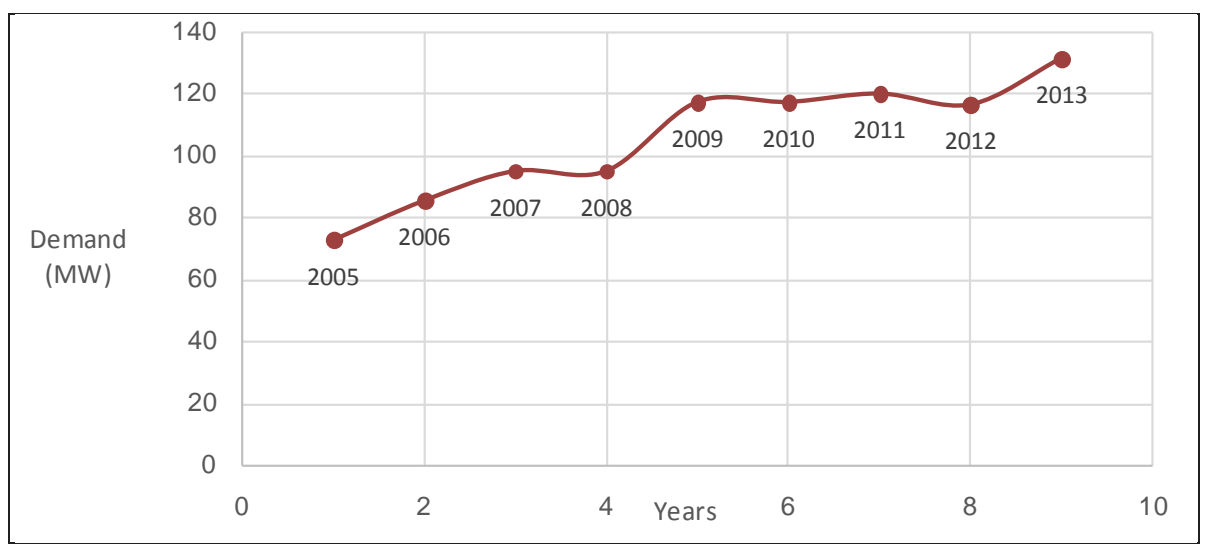

Figure 10. Total max demand. 
Table 13. Max demand of Aqaba governorate for nine years.

\begin{tabular}{ccccccccccc}
\hline City & & $\mathbf{2 0 0 5}$ & $\mathbf{2 0 0 6}$ & $\mathbf{2 0 0 7}$ & $\mathbf{2 0 0 8}$ & $\mathbf{2 0 0 9}$ & $\mathbf{2 0 1 0}$ & $\mathbf{2 0 1 1}$ & $\mathbf{2 0 1 2}$ & $\mathbf{2 0 1 3}$ \\
\hline \multirow{3}{*}{ Aqaba } & Industrial East & 1.08 & 27.28 & 30.16 & 38.32 & 47.68 & 47.68 & 26.64 & 23.00 & 27.28 \\
& $\mathrm{~A} 2$ & 50.07 & 35.73 & 37.08 & 33.62 & 30.03 & 30.03 & 42.44 & 33.27 & 51.65 \\
& Thermal & 8.52 & 9.46 & 11.79 & 14.83 & 22.72 & 22.72 & 21.73 & 23.73 & 17.71 \\
& Guweira & 13.05 & 13.07 & 15.25 & 14.78 & 15.95 & 15.95 & 16.22 & 15.46 & 17.48 \\
& Aqaba Total & $\mathbf{7 2 . 7 3}$ & $\mathbf{8 5 . 4 7}$ & $\mathbf{9 5 . 0 3}$ & $\mathbf{9 5 . 0 3}$ & $\mathbf{1 1 7 . 2 3}$ & $\mathbf{1 1 7 . 2 3}$ & $\mathbf{1 1 9 . 9 3}$ & $\mathbf{1 1 6 . 4 7}$ & $\mathbf{1 3 1 . 4 9}$ \\
\hline
\end{tabular}

Table 14. Least squares co-officiant.

\begin{tabular}{ccccccc}
\hline Last Years & $\mathbf{M a x} \boldsymbol{D}$ & $\boldsymbol{D}_{\boldsymbol{i}}^{\prime}=\mathbf{D} / \mathbf{1 0}$ & $\boldsymbol{V}_{\boldsymbol{i}}=\mathbf{l n} \boldsymbol{D}_{\boldsymbol{i}}^{\prime}$ & $\boldsymbol{Y}_{\boldsymbol{i}}$ & $\boldsymbol{V}_{\boldsymbol{i}} \boldsymbol{Y}_{i}^{\prime}$ & $\boldsymbol{Y}_{\boldsymbol{i}}^{\wedge} \mathbf{2}$ \\
\hline $\mathbf{2 0 0 5}$ & 72.73 & 7.273 & 1.984169 & -4 & -7.93668 & 16 \\
$\mathbf{2 0 0 6}$ & 85.47 & 8.547 & 2.14558 & -3 & -6.43674 & 9 \\
$\mathbf{2 0 0 7}$ & 95.03 & 9.503 & 2.251608 & -2 & -4.50322 & 4 \\
$\mathbf{2 0 0 8}$ & 95.03 & 9.503 & 2.251608 & -1 & -2.25161 & 1 \\
$\mathbf{2 0 0 9}$ & 117.23 & 11.723 & 2.461553 & 0 & 0 & 0 \\
$\mathbf{2 0 1 0}$ & 117.23 & 11.723 & 2.461553 & 1 & 2.461553 & 1 \\
$\mathbf{2 0 1 1}$ & 119.93 & 11.993 & 2.484323 & 2 & 4.968646 & 4 \\
$\mathbf{2 0 1 2}$ & 116.47 & 11.647 & 2.455049 & 3 & 7.365146 & 9 \\
$\mathbf{2 0 1 3}$ & 131.49 & 13.149 & 2.576346 & 4 & 10.30538 & 16 \\
\hline
\end{tabular}

Table 15. Max demand for next ten years.

\begin{tabular}{cccccc}
\hline Next Years & Sum of $V_{i}$ & Sum of $Y_{i}$ & Sim of $V_{i} Y_{i}$ & $a$ & Max $D$ \\
\hline 2014 & & & 144.73949 \\
$\mathbf{2 0 1 5}$ & & & 154.64678 \\
$\mathbf{2 0 1 6}$ & & & 165.23221 \\
$\mathbf{2 0 1 7}$ & & & & 176.5422 \\
$\mathbf{2 0 1 8}$ & 21.0717872 & 0 & 3.97248867 & 188.62635 \\
$\mathbf{2 0 1 9}$ & & & 2.34131 & 201.53765 \\
$\mathbf{2 0 2 0}$ & & & 215.33272 \\
$\mathbf{2 0 2 1}$ & & & 230.07205 \\
$\mathbf{2 0 2 2}$ & & & 245.82027 \\
$\mathbf{2 0 2 3}$ & & & 262.64644 \\
\hline
\end{tabular}

on the axis, then we have to generate the curve in Figure 11.

After we found the values of Max demand of next years, we predicted the year for which you want the new plant, in next page Table 16 and Table 17 show this.

When we see to Table 16 and Table 17, not found any value of Demand is between 85\% - 90\%, for ten years we not need a new plant for Al-Aqapa city.

\section{Conclusion}

This paper presents long-term load forecasting of Southern Governorates of Jordan Distribution Electric System 


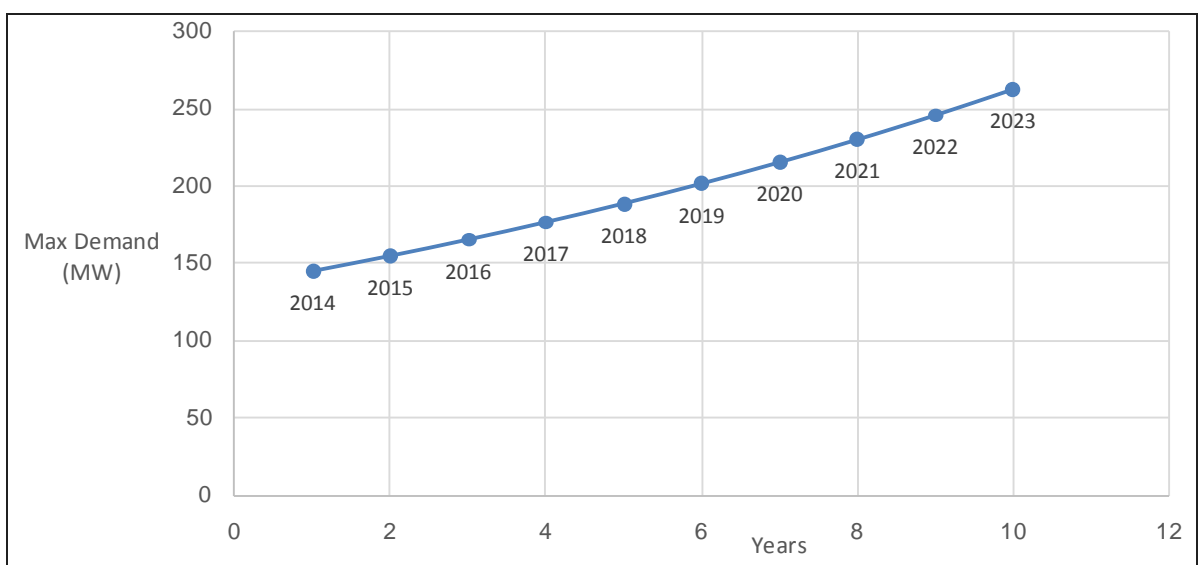

Figure 11. Next ten years forecasting of Aqaba

Table 16. Aqaba forecasting for 10 years.

\begin{tabular}{|c|c|c|c|c|c|c|c|c|c|c|c|}
\hline 2023 & 2022 & 2021 & 2020 & 2019 & 2018 & 2017 & 2016 & 2015 & 2014 & $\operatorname{Max} D$ & Sub \\
\hline 106.78 & 98.83 & 90.88 & 82.93 & 74.98 & 67.03 & 59.08 & 51.13 & 43.18 & 35.23 & 150.4 & Industrial Estat \\
\hline 93.41 & 89.23 & 85.06 & 80.88 & 76.71 & 72.53 & 68.35 & 64.18 & 60 & 55.38 & 131.56 & A2 \\
\hline 52.256 & 48.8 & 45.35 & 41.89 & 38.44 & 34.98 & 31.53 & 28.07 & 24.64 & 21.16 & 73.6 & Thermal \\
\hline 10.204 & 8.96 & 8.68 & 9.63 & 11.41 & 14.09 & 17.58 & 21.85 & 26.83 & 32.97 & 15.52 & Guweira \\
\hline 262.65 & 245.82 & 230.07 & 215.33 & 201.54 & 188.63 & 176.54 & 165.23 & 154.65 & 144.74 & 371.08 & aqapa Total \\
\hline
\end{tabular}

Table 17. Total max demand of southerner governorates of Jordan distribution electric system forecast 2014-2023.

\begin{tabular}{cccccccccccccc}
\hline $\mathbf{2 0 2 3}$ & $\mathbf{2 0 2 2}$ & $\mathbf{2 0 2 1}$ & $\mathbf{2 0 2 0}$ & $\mathbf{2 0 1 9}$ & $\mathbf{2 0 1 8}$ & $\mathbf{2 0 1 7}$ & $\mathbf{2 0 1 6}$ & $\mathbf{2 0 1 5}$ & $\mathbf{2 0 1 4}$ & Max of Sub & City & Aqapa \\
\hline 262.65 & 245.82 & 230.07 & 215.33 & 201.54 & 188.63 & 176.54 & 165.23 & 154.65 & 144.74 & 371.08 & Aq \\
172.14 & 160.89 & 150.38 & 140.56 & 131.38 & 122.79 & 114.77 & 107.27 & 100.27 & 93.716 & 75.04 & Karak \\
96.77 & 85.55 & 75.63 & 66.86 & 59.11 & 52.25 & 46.19 & 40.84 & 36.1 & 31.92 & 53.94 & Tafila \\
91.43 & 85.6 & 80.14 & 75.03 & 70.25 & 65.77 & 61.57 & 57.65 & 53.97 & 50.53 & 68.39 & Maan \\
622.99 & 577.86 & 536.22 & 497.78 & 462.28 & 429.44 & 399.07 & 370.99 & 344.99 & 320.906 & 568.45 & Total
\end{tabular}

based on least squares method by finding the Max Capacity of all Substations for each city and finding total Max capacity for that substations, and total Max Demand of South area. In 2020, the Max Demand of south between 85\% - 90\% from Max capacity in this year, to cover the expectoration for upcoming load we recommend to build new plant for the South Jordan to be ready to operate in end of 202. Also the max demand will be at Aqapa 262.65 MW and total max demand at all Southern Governorates will equal 622.99 MW. The forecast in Aqapa calculated based on all proposed upcoming industrial projects. Under this scenario, the forecasted peak load in 10years' time is $262.65 \mathrm{MW}$.

\section{References}

[1] Singh, A.K., Ibraheem, Khatoon, S. and Muazzam, Md. (2013) An Overview of Electricity Demand Forecasting Techniques. National Conference on Emerging Trends in Electrical, Instrumentation \& Communication Engineering, 3, 38-34.

[2] Ghods, L. and Kalantar, M. (2011) Different Methods of Long-Term Electric Load Demand Forecasting; A Comprehensive Review. Iranian Journal of Electrical \& Electronic Engineering, 7, 249-259.

[3] Feilat, E.A. and Bouzguenda, M. (2011) Medium-Term Load Forecasting Using Neural Network Approach. 2011 
IEEE PES Conference on Innovative Smart Grid Technologies - Middle East (ISGT Middle East), Jeddah, 17-20 December 2011, 1-5.

[4] Daneshi, H., Shahidehpour, M. and Choobbari, A.L. (2008) Long-Term Load Forecasting in Electricity Market. IEEE International Conference on Electro/Information Technology, 2008. EIT 2008, Ames, 18-20 May 2008, 395-400.

[5] Nahari, A., Rostami, H. and Dashti, R. (2013) Electrical Load Forecasting in Power Distribution Network by Using Artificial Neural Network. International Journal of Electronics Communication and Computer Engineering, 4, 17371743.

[6] Aslan, Y., Yavasca, S. and Yasar, C. (2011) Long Term Electric Peak Load Forecasting Of Kutahya Using Different Approaches. International Journal on Technical and Physical Problems of Engineering, 3, 87-91.

[7] Badran, S.M. and Abouelatta, O.B. (2011) Forecasting Electrical Load using ANN Combined with Multiple Regression Method. The Research Bulletin of Jordan ACM, 2, 52-58.

[8] Kavehnia, F., Keivani, H. and Mohammadi, A. (2007) Long Term Demand Forecast for an Electricity Distribution Network. Power Engineering Conference, 2007. AUPEC 2007. Australasian Universities, 1-6.

[9] Amjady, N. and Daraeepour, A. (2010) Midterm Demand Prediction of Electrical Power Systems Using a New Hybrid Forecast Technique. IEEE Transactions on Power Systems, 26.

[10] Wang, J.J., Niu, D.X. and Li, L. (2010) Middle-Long Term Load Forecasting Based on Dynamic Architecture for Artificial Neural Network. Journal of Information \& Computational Science, 7, 1711-1717.

[11] Aslan, Y., Yavasca, S. and Yasar, C. (2011) Long Term Electric Peak Load Forecasting Of Kutahya Using Different Approaches. International Journal on Technical and Physical Problems of Engineering, 7, 87-91.

[12] Saraereh, O.A., Alsafasfeh, Q., Al Tarabsheh, A., Arfoa, A. and Etier, I. (2014) Least Squares Fitting Based Fault Classification in Distribution Systems. Journal of Energy and Power Engineering, 8, 560-567.

[13] Electricity Distribution Company (EDCO) 2013-2007. http://www.edco.jo/index.php/using-joomla-2/extensions-2/media-center/reports 